\section{Hannah Arendt e a dignidade da política}

Adriano Correia. Hannah Arendt e a modernidade: política, economia e a disputa por uma fronteira. Rio de Janeiro, Forense Universitária, 2014. 256 páginas.

Glauber Lopes Xavier

Em suma, não pode haver em uma comunidade politica legítima uma ruptura entre a práxis que gesta o poder e a práxis que é o próprio exercício do poder. Após a fundação não deve cessar a práxis e começar a gestão, pois a razão de ser da instituição das comunidades políticas é, para Arendt, não a administração da vida social, mas a preservação de um espaço público de participação política no qual a liberdade possa aparecer. A razão de ser da fundação é a conservação, via institucionalização, $d a$ práxis originária gestadora do poder. Por isso Arendt jamais identificaria o exercício do poder politico nas instituições de uma determinada comunidade política com uma relação de dominação. Mais ainda, não consideraria legitimo poder politico algum desligado de sua práxis originária, como também não consideraria vigorosa comunidade politica alguma que não fosse capaz de reificar essa práxis em instituiçôes jurídicas capazes de atualizá-la permanentemente.

Adriano Correia

Em obra recentemente publicada pela Forense Universitária, a qual traz como título Hannah Arendt e a modernidade: politica, economia e a disputa por uma fronteira, Adriano Correia, professor da Faculdade de Filosofia da Universidade Federal de Goiás, percorre uma série de questóes dispostas no pensamento daquela que repelia ser identificada por filósofa, ao que argumentava ter como ofício a teoria política, Hannah Arendt. Inicia primoroso trabalho apresentando um breve prólogo, no qual expõe as principais inquietações da pensadora e, assim, aponta suas principais contribuições. Neste prólogo fica claro por que Arendt dirigia seus esforços à dimensão política do ser, seara geralmente hostilizada pela filosofia. A ação, no mundo, é o que movia os escritos da pensadora de origem judaica, perseguida pelo nazismo. Com efeito, contemplar a ação dos sujeitos consiste em tomar o homem como ser cuja realização se dá entre outros homens e não isoladamente, daí o esforço de compreensão da realização humana, de suas ações na terra tratar-se de um aspecto fulcral de seu fecundo e estimulante pensamento.

Correia, com uma escrita bastante clara, mostra que não se pode dissociar a compreensão dos escritos de Arendt e os acontecimentos históricos, os quais não apenas animaram suas empreendidas, mas estão no âmago de seus constructos teóricos e de suas reflexões. Assim, do prólogo é possível sublinhar alguns conceitos que sustentam as reflexões de Hannah Arendt e que são retomados por Correia no decurso da obra, tais como: verdade, comunicação, pensamento, ação. Importa, por fim, com base em Arendt, compreender o que o homem tem realizado no mundo, como tem realizado, como tem sido edificada a condição humana levando-se em conta os limites históricos e do próprio pensamento.

A obra está organizada em oito capítulos, além do prólogo e de um epílogo. A reflexão em torno da relação entre economia e política na modernidade permeia boa parte da obra, tanto em uma perspectiva que explora os pressupostos filosóficos que ancoram o pensamento de Hannah Arendt, quanto em uma que problematiza a crise da civilização com o advento da modernidade a partir das contribuições arendtianas arroladas em seus escritos políticos. Em linhas gerais, Correia elucida como o pensamento de Hannah Arendt, e para tanto promove fecundo diálogo com outros autores, descortina o mundo moderno tomando por base o ocaso da política promovido pelo triunfo de uma economia cuja centralidade é o consumo e cujo substrato é o animal laborans, subjugado aos ditames da produção de mercadorias e à burocracia, modelo ideal de tirania, pois que supostamente exercida de forma neutra, autônoma e desprovida de agentes.

A partir da obra, fica claro que as análises empreendidas por Hannah Arendt extrapolam o âmbito do processo de produção das obras e dos objetos e atinge o plano da produção de sua existência, da edificaçãao de sua condição e de sua morada. Assim, conforme aponta Correia, enfatizando o zelo de Arendt no tratamento dos conceitos, cinco entre os vários mobilizados e perscrutados pela autora sintetizam ou expressam a essência da condição humana: natalidade, mortalidade, mun- 
danidade, pluralidade e terra. A natalidade está associada ao primado da própria política, a ação, portanto ao pensamento político; a mortalidade, por sua vez, diz respeito ao pensamento metafísico. A pluralidade consiste na própria essência da política, isto é, a tessitura da vida em coletividade a partir das particularidades e da diversidade que conforma os indivíduos.

A pluralidade é condição sine in qua non para a dignidade da política, portanto para a liberdade, dando sentido à vida e à terra. A terra, nesse particular, consiste na relação homem-natureza (physis). Ainda conforme o autor, três acontecimentos foram determinantes para alterar tal condição, as quais ensejaram a modernidade, segundo Hannah Arendt: a descoberta da América, a Reforma Protestante e a invenção do telescópio. $\mathrm{O}$ aspecto central destacado pelo autor acerca das reflexões arendtianas consiste na alienação humana decorrente dos fatores condicionantes da modernidade, especialmente a racionalidade instaurada pelo primado da ciência.

Além disso, e valendo-se das comparações com o cão de Pavlov, Correia mostra que o consumo - ação por excelência da alienação do homem na modernidade - vem a ser uma espécie de reflexo condicionante que compromete a autonomia da ação, na medida em que o reduz a uma espécie de autômato. Recorre, por seu turno, a vários autores a fim de imiscuir as reflexões no âmbito das fronteiras entre economia e política na modernidade e as contribuições do pensamento de Hannah Arendt. De Foucault ressalta o assento da razão econômica ao tratar de sua biopolítica, ademais da afirmação do homo oeconomicus. De Agamben, a relação entre zoé e bios, ou seja, a politização da vida, a política da vida, obnubilada pela suposta racionalidade de caráter eminentemente econômico. O cerne de uma biopolítica e de uma vida nua, conforme Agamben, residiria no animal laborans, contribuição fenomênica do pensamento de Arendt para se conceber a relação entre o homem e o mundo.

O desdobramento político desse animal laborans, dada a dissolução das classes, das identidades políticas e, portanto, de suas representações e referenciais, consiste nas chamadas sociedades de massas, muitas das quais resultaram em regimes totalitários. A sociedade de massas a que se refere Hannah Arendt cimentou-se com o ascenso da esfera social. Ao tratar desse fenômeno em sua obra, Correia problematiza o que ele aponta como fronteiras inerentes à modernidade, as quais ocupam o pensamento contemporâneo e estão, a seu modo, delineadas nas reflexôes arendtianas sobre sociedade, economia e política na modernidade. Embora Correia não tenha levado em conta o conceito de sociedade civil ao promover o diálogo entre Hannah Arendt e Michel Foucault, com base nele é possível abstrair a crítica de Arendt ao imperativo da dimensão social, a qual poderia, na esteira das reflexōes arendtianas, sublimar a política e, assim, comprometer seus pilares.

A possibilidade de diálogo entre Foucault e Arendt a partir do conceito de sociedade civil do primeiro e da crítica da dimensão social da segunda está em que, sem a chamada sociedade civil, não seria possível a emergência de um modelo de gestão das populações encetado pelo Estado-nação moderno, o que o filósofo francês denomina governamentalidade, cujo aspecto central consiste em uma economia como dispositivo de controle social, de tecnologia de governo. Esta seria apenas uma entre várias possibilidades de um debate entre Arendt e Foucault. A propósito das críticas recebidas por parte dos leitores de Hannah Aren$\mathrm{dt}$, Correia perscruta, com acuidade, o seu pensamento a fim de explorar cada uma delas e expor em quais aspectos muitas se apresentam frágeis e, portanto, insustentáveis.

Ao ressaltar a ameaça da instância social sobre a política, Arendt não advogava a existência de um ideal de política, desprovida de conflitos da ordem material da vida, mas uma política com dignidade, em que a liberdade fosse o valor supremo. Embora Correia não tenha aprofundado essa questão, sua obra apresenta-se como um ponto de partida aos que intencionam apreender a crise política e os aspectos psicossociais envolvidos, deflagrada pela primazia do mercado e calcada em um modelo de sociedade em que o individualismo, o consumismo e a derrocada da esfera pública são traços amiúde evidentes.

Ainda sobre as interlocuções promovidas por Correia, após Foucault e Agamben, o autor traz 
Habermas para o debate. Promove, com êxito, uma exposição das conclusões habbermasianas sobre o conceito de poder e a questão da justiça em Hannah Arendt e aponta, fundamentalmente, os equívocos cometidos pelo filósofo alemão. Se, por um lado, Habermas ressalta a fecundidade do conceito de poder em Arendt, o qual é relacional e converge para o assentimento e não apenas como afirmação do domínio que se exerce, por outro, sua pretensão de "transpor o horizonte por ele denominado normativo na compreensão de Arendt em direção a um exame do que nomeia de utilidade científica com vistas à adequação do conceito para fins descritivos" (p. 160) pôe por terra qualquer possibilidade de compreensão do sentido da política em Hannah Arendt.

A impossibilidade de aplicabilidade dos escritos de Arendt está em que seu pensamento não se opera com base no modelo de sociedade vigente a partir de como esta poderia se modificar, pretensão da teoria social e da ciência, o que não implica no divórcio entre pensamento e realidade, teoria e práxis, mas na assunção de que a crise da política retirou-lhe o que ela contém de fundamental, a possibilidade da ação humana em uma esfera pública, sendo a liberdade seu valor supremo da condição humana. Nas palavras de Correia: "Para os leitores de $A$ condição humana fica claro que, para Arendt, essa inaplicabilidade apenas reforça suas hipóteses com relação ao declínio da política na era moderna” (p. 163).

$\mathrm{O}$ autor segue em suas críticas às objeções lançadas por Habermas, ao elucidar que, diferentemente da interpretação habermasiana de que teoria e prática se encontram cindidas no pensamento de Hannah Arendt, a práxis é o substrato de qualquer movimento revolucionário, sem a qual não é possível que este seja sucedido pela fundação de um novo regime político e ainda se mantenha vivo e pulsante. Correia encerra a obra com um epílogo, em que versa sobre a crença de Hannah Arendt na política como ação de liberdade, tendo encontrado, nos conselhos, um modelo de participação política vertiginosamente transformador e potencialmente revolucionário. Com efeito, os conselhos reservariam, assim, a dignidade da política.

\section{Glauber Lopes Xavier é doutor em sociologia pela Universidade Federal de Goiás. Realizou estágio pós-doutoral no Programa de Pós-graduação de Ciências Sociais da Universidade Federal Rural do Rio de Janeiro (CPDA/UFRRJ). É professor-adjunto da Universidade \\ Estadual de Goiás e bolsista do Programa de Incentivo ao Pesquisador (Probip) da mesma instituição. E-mail: glauber. xavier@ueg.br/glauberlx@hotmail.com.}

DOI: http//dx.doi.org/10.17666/3088191-193/2015 